\title{
The Education Strategy Analysis of University Network Literacy Based on Internet Rumors
}

\author{
Ming Qi ${ }^{*}$, Lihui Ding \\ School of Electrical and Information Engineering, Jiangsu University, Zhenjiang, China \\ Email address: \\ qiming@ujs.edu.cn (Ming Qi), lihuiding@foxmail.com (Lihui Ding) \\ ${ }^{*}$ Corresponding author
}

To cite this article:

Ming Qi, Lihui Ding. The Education Strategy Analysis of University Network Literacy Based on Internet Rumors. Education Journal. Vol. 7, No. 5, 2018, pp. 115-121. doi: 10.11648/j.edu.20180705.12

Received: August 27, 2018; Accepted: October 12, 2018; Published: November 6, 2018

\begin{abstract}
The advent of the Internet era has changed the way people get information. As a common phenomenon of social opinion, rumor forms a new force combined with the Internet, which no longer confined to specific groups, specific space-time, specific scope of transmission, its speed of transmission and impact increases quickly. Internet rumors have the characteristics of multi-subject, virtuality and emotional incitement, which have negative impacts on the value orientation, moral behavior and sense of responsibility for young students. College students, as the future builders of the country, their establishment of correct values, the cultivation of ethics and morality and the level of civic awareness directly affect the establishment of social order. Therefore, colleges and universities should take active steps to value students' network literacy education, cultivate students' awareness of the instrumentality and practicality of the network, maintain rational and critical cognition in the network information, and understand the characteristics of interactivity and the public opinion guidance of network information dissemination. The above aims are to improve young students' ability to identify network consensus, and reduce or even eliminate the impact of Internet rumors on young students. Young students should correctly understand the harm of Internet rumors, resist them and maintain network security and social stability.
\end{abstract}

Keywords: Internet Rumors, Network Literacy, Education Strategy

\section{Introduction}

With the advent of the new media era, the Internet has become the main channel for the Chinese people to obtain information and free speech. However, due to its openness, equality and immediacy, it may produce malignant phenomena such as information security, cyber violence, network hype and Internet rumors, which will endanger national security and social order [1]. Under the current risk society form of the transformation of economy and society, the change of social structure, inadequate power regulation and the decrease of interpersonal trust have caused a series of social problems, and have brought about negative social feelings of the public. Therefore, Internet rumors have become an important carrier for the public to express and release of discontent about social issues [2]. Young students show great enthusiasm and superiority in the participation, creation, dissemination and acceptance of network information. However, due to their immature emotional, psychological and political qualities, and their lack of recognition ability for online speech, they often follow blindly to monger or even spread rumors, which make them become the important group to disseminate online public opinion [3].

The governments have issued rules separately to promote healthy and orderly developments of Internet. To resist Internet rumors, many researchers have proposed some suggestions, including improving the transparency of information, establishing multi agent cooperation mechanism, and strengthening the supervision of network. These above-mentioned suggestions are proposed for the government and network supervision departments. Different from them, the educators, as the governors of universities, should propose the unique education method for young college students according to the features of Internet rumors. Hence, this paper conducts a research to explore the methods on how to improve the network literacies of college students, maintaining their objectivity and independence when exposed to Internet rumors. 


\section{Literature Review}

As can be found in the related literature, the study on rumors can be traced back to the Second World War of the last century. With the advent of the Internet era, rumors have more new characteristics, and the impact is even worse. A lot of researches have done by the scholars on Internet rumors. It is worth noting that the popularization of Internet in Europe and America is much earlier than that in China, but the research content of response measures to solve the Internet rumor are less involved, which is attributed to the relatively complete policies about solving Internet rumors[4].

Jiang [5] analyzed the Internet rumors from the angle of public opinion guidance, and further put forward to protect people's livelihood needs, safeguard the interests of the masses, and insist on transparency of information. In addition, the government's need to actively understand the needs of the masses, while giving the people full right to know. According to the characteristics of international comparative Internet rumors, Wang [6] pointed out that the success of many countries in dealing with Internet rumors depends to a great extent on their long-term commitment to law and system construction. Establishing relevant laws and regulations are to ensure the construction of Internet. Chen [7] hold that we should focus on innovative technology, enhance the ability and level of technical supervision, promote the real-name registration of the Internet and strengthen the supervision of public surfing places. More and more scholars pay attention to the college students' cognition of Internet rumors. Wang [8] indicated that we should strengthen the propaganda of the mainstream ideology, stabilize the ideological foundation of students, and strengthen the construction of campus sanitation culture to build network standards. Cao [9] supported that the university online opinion leaders with strong personality charm, wide influence and guide correct public opinion will make them become accompany students' growth. Consequently, the education strategy of the network literacy based on the Internet rumors has great significance for university students.

\section{The Connotation of Internet Rumors}

\subsection{The Definition of Internet Rumors}

The Merriam Webster Dictionary points out that rumors are gossip, hearsay or public opinion, which are not authentic or proved and it is difficult for the public to tell the truth. According to American social psychologists Gordon Albert and Leo Postman "rumors are propositions related to the events of the time, intended to convince people that they are generally spread among people through the media, but there is no specific information to confirm their exact elaboration or interpretation"[4]. The definition from the French scholar Jean-Joel Capfrey is also widely accepted. He believes that rumors are "information that emerges and circulates in society, which has not been officially publicly verified or has been officially disproved" [11]. American sociologist T. Hibtani examines rumors from a sociological point of view, saying that "rumors are impromptu news that arise during a group of people talking." He believed that rumors originated from an important and complicated event[12]. Despite insisting different opinions, most scholars generally regard " unsubstantiated " as the essential characteristic of rumors. The traditional way of spreading rumors is interpersonal communication, which carries out transmission of the unconfirmed information on issues of public concern or interest. In most cases, rumors contain many false, exaggerated and misinformed elements. The spread and influence of rumors are often in direct proportion to the importance of rumors, the opacity of the events and the interest from the audience, and inversely proportional to the degree of public rationality. At the same time, they are influenced and restricted by the social environment and social communication mechanism.

Scholars' research on Internet rumors is based on rumor research. Internet rumors are rumors generated or spread through computer networks. Internet rumor is also the rumor in essence, and the most important characteristic that distinguishes it from the general rumor is that its communication channel changes from oral communication to the multimedia information communication, which results in many new features. Judging from the content of the current network rumors, there are both libels against individual citizens and fabrications against public events, which have the characteristics of concealment, speculation, aggression, retaliation, catharsis, temptation, compulsion.

\subsection{The Classification of Internet Rumors}

There are various types of Internet rumors, and can be divided into many different types according to different angles. Internet rumors can be divided into political rumors, economic rumors, military rumors, social life rumors and natural phenomenon rumors from the content. Political rumors are about political life, which are the products of the struggle of political power and interests, often deliberately fabricated for a certain political need. Political rumors are attacks and slanders on the political figures or groups concerned. Economic rumors are about economic life, which are often related to economic interests and will directly lead to economic gains or losses. Military rumors are about military life and military operations, which tend to be crazy in the war years. Rumors of natural phenomena are mainly related to the special phenomena of nature and mysterious phenomena of the universe, and rumors of aliens or natural disasters are most common. Internet rumors also can be divided into intentionally fabricated rumors and unintentional misleading rumors from purpose. Intentionally fabricated rumors are often fabricated by the manufacturer for specific purposes and targets driven by some kind of interest. Unintentional misleading rumors result from a variety of reasons in the process of news transmission, there are omissions, reversals or errors. Such incorrect propagation caused by fiction, association and exaggeration can easily become the source of rumors. At the same time, rumors can be divided into harmful rumors and harmless rumors from the consequences. Rumor is 
a political and social phenomenon, is a special form of public opinion and the negative form of public evaluation activities.

\subsection{Characteristics of the Spreading of Internet Rumors}

\subsubsection{Multiple Propagating Subjects of Internet Rumors}

The propagating subjects of Internet rumor dissemination refer to the summation of all kinds of subjects, who express their emotions, attitudes and wishes on the emergencies and hot events involved in Internet rumors. The propagating subjects' structure of the Internet rumors spread here is not single, but subdivided. For example, according to the propagating subjects' cultural level, occupation, the degree of influence on Internet rumors and so on. Some propagating subjects of the Internet rumors are premeditated to monger, leading and guiding the spread of rumors, and influencing the development of rumors. However, the vast majority of the Internet rumor disseminator in the network just receives other's guidance, inadvertently monger rumors, and play a role of echoing Internet rumors. Therefore, every netizen has the possibility to become the propagating subject of Internet rumors mongering. In the traditional spread process of rumors, opinion leaders or organizations with the right to speak will generally hold and promote the key information of rumors. But the greatest impact of the Internet on society is "decentralization of power", which is achieved through the right of everyone to disseminate information in the network [3]. According to The 41st China Statistical Report on Internet Development issued by China Internet Network Information Center (CNNIC) in December 2017, the number of Internet users reached 772 million, with the Internet penetration rate of $55.8 \%$. The proportion of rural netizens was $27 \%$ and 209 million, and the proportion of Internet users using mobile Internet was $97.5 \%$. Such a huge scale and demographic characteristics difference of Internet users in the process of information dissemination, many netizens will not deliberately distinguish whether the information violates political, economic or social common sense, but will disseminate some novel and eye-catching content. Meanwhile, the convenience brought by mobile phones guide them unintentionally become the disseminators of rumors.

\subsubsection{Breaking the Traditional Social Order of Acquaintances by the Virtual Nature of the Network}

Before the popularization of Internet technology, the rumors were mainly spread by word of mouth among acquaintances. In the Internet age, especially with the rapid development of new media technology and the continuous emergence of new forms, the spread of rumors has shifted to alternate switching between strangers, acquaintances, acquaintances and strangers. Strangers gather together because they pay close attention to the same event and information, and the information they see on the website, BBS, blog, Twitter and other public communication channels will be forwarded to Facebook, WeChat QQ group and other interpersonal communication channels, and then the information will go from the online world to offline life through chatting among acquaintances. The unique identity fictitiousness of the communicating groups in the Internet world makes the communicating behavior of the network less interdependent than the social communication in the real world. The vulnerability of the individual in the process of the network communication can be weakened to a certain extent, so the fictitious social communication is sometimes even more interdependent than the real social communication. Communication is more intimate and abundant, when the real social communication behavior is often manifested as the conflict and exchange of interests. However, the communication behavior in the virtual world is mostly based on the common interest, which makes it different from the limitation and compulsion of social communication in the real world. The spread of rumors in the network is like "throwing rocks into the water", the superimposed energy of the water waves scattered by the various centers is much higher than that of the single center of rumors [14]. Therefore, the Internet rumor dissemination source is multi-subject, the dissemination channel is diversified, multi-subject dissemination source and the form of online and offline interactive dissemination brings great difficulties to clarify the structure of rumor dissemination.

\subsubsection{Emotional Mobilization Is An Important Mechanism for the Spread of Internet Rumors}

The function of emotional mobilization is to transform simple viewers into close-knit collective actors to promote highly consistent thinking and action among dispersed individuals. And anger, sympathy and playfulness are the best catalysts for public emotional resonance. In a short period of time, the influence of Internet rumors has expanded geometrically, and the social harmfulness has been magnified rapidly, which may produce unpredictable results. Emotional resonance promotes frequent interaction between netizens and the spread of Internet rumors. In the face of the widely discussed and concerned Internet rumors, more netizens tend to "starting from emotional resonance, not from the facts" in the absence of information authenticity. Research shows that rumors on the Internet are mostly determined by the interaction of the netizens rather than by the pushers or leaders, for which the emotional resonance of netizens is the fundamental reason for the spread of Internet rumors. Remarkably, social risk is frequent and negative "collective memory" is formed. Most of the rumors focus on public security, social equity and government credibility, and the most common ones are social risks problems such as allocation of social resources, interest distribution, incorruption of government, integration of urban and rural areas, and political participation of the masses. Although the information content of the rumors have been severely distorted in the process of multiple spread. However, the Internet rumors always seem to be able to mobilize public emotions, and some negative emotions have been precipitated to form a "collective memory" in the public mind [15]. Under the circumstance that the public has a personal judgment about certain events and scenes that deviates from the facts, the 
information or events carried by Internet rumors arouse the collective memory of the people, and the reproducing and copying of information by the netizens resonate with the collective memory again. If it is easy for the public to express their discontent and anger towards society by spreading rumors through word of mouth, Obviously, Internet rumors have brought this function into full play in the Internet era.

\section{The Influence on Young Students of Internet Rumors}

Nowadays, social conflicts social problems are increasing, because society is in the transition. Internet rumors appear in some social emergencies and major events, which not only affects the operation of the network order, but also has a certain impact on the stability of the whole society. As a special social group, college students are influenced by their special physiological and psychological characteristics. Their self-awareness develops rapidly, full of enthusiasm. They are courage to innovate and show the rebellion against traditional and mainstream culture, unusual sensitivity and acceptance of new ideas, and often with innovative language and behavior to show their own distinctive. At the same time, Internet rumors have an immeasurable influence on the value orientation, moral behavior and lifestyle of young college students whose minds are not yet fully mature.

\subsection{Internet Rumors can Lead to Misplacement of College Students' Values.}

Value orientation refers to the attitude or position chosen in the face of various relationships. In the modern society of informationization, the influence of Internet rumors can determine people's life choice to some extent, which controls people's social psychological state by influencing people's intuition. Intuition is a combination of psychological factors and emotional factors. Compared with rationality, intuition directly participates in value judgment by feeling and appearances with the needlessness of thorough theoretical deduction and logical operation. Intuition makes harsh or even false judgments about the object of value based on limited information alone. Because of the high degree of freedom and personalization of the Internet, rumors propagators can arbitrarily place their subjective preferences and dislikes in rumors, distort reality and selectively express personal narrow and wrong values, which directly affect young students' first intuition of things and give them an illusion that things deviate from normal choices with false information. As a result, they may influence individual choice and judgment in the complex social interaction system constructed by the new media. In addition, the characteristics of the mass life of college students, the emotions of individual members who are confused by rumors will drive more members, and eventually, it is easy to trigger the "snowball effect" and "group polarization events"[16].

\subsection{Internet Rumors can Lead to the Confusion of College Students' Ethics and Morality.}

Due to the differences in gender, age, family background and emotional experience, different students have different ethical and moral concepts and different understandings and opinions about the same event, which makes them in the need of the influence from mainstream ideology. However, the authority is no longer the only channel to regulate ethics and morality in the information age. And the network also plays a pivotal role in the process of ethics and morality dissemination. In the period of traditional media, the main ways for students to receive ethical and moral education are from authoritative teachers and official media in the educational places. Instead, with the advent of the Internet age, students can receive values education through various channels. In the virtual world, every subject can distribute, comment and transmit all kinds of false information without restriction. When the ethics and morality of Internet rumors collide with the original ethical cognition, students will have the question about the original ethics and morality understood by authoritative organizations, which also sets up obstacles for them to receive correct ethical and moral education. Invariably, they are in the midst of all kinds of rumors, and various contrary remarks disturb their way of thinking and judgment, causing them to be easily trapped in the dilemma of ethics and morality.

\subsection{Internet Rumors can Lead to a Weak Sense of Responsibility Among College Students.}

Because of the unbalanced development of the new media and the network accountability system, the netizens who maliciously create and monger Internet rumors are often not subject to moral condemnation and legal sanctions. This phenomenon will make college students mistakenly believe that Internet rumors need not bear any consequences, so that they lose the sense of responsibility corresponding to the reality. They only focus on the enjoyment of rights but lack of the sense of responsibility, which makes them override the citizenship, over-exaggerate the freedom of rights, and arbitrarily create public opinion and emotional environment. At the same time, college Internet users are prone to make a herd reaction to the ambiguous and irritating subjects. In the process of conformity, one of the reasons for people to flee is the dispersion of individual responsibilities. When a person acts alone, he or she often considers whether it is moral. When the groups work together, the responsibility will be scattered to everyone. Individuals do not have to bear the condemnation incurred by this activity and feel freer to do what they want to, which results in the lessening of individual shame and the loss of responsibility. Once this idea is deeply rooted, college students will become more and more reckless in the face of Internet rumors, and the long-standing fluke psychology will cause college students to avoid responsibility.

\section{Education Strategy of Network Literacy in Universities}

The development of the network is not relocated by the will of man, and its influence, whether positive or negative, is unavoidable. Hence, what the college education should do is 
not to avoid and block the network, but to let college students know how to effectively use the network media. In addition, the college students should be encouraged to conduct reasonable evaluations and scientific managements of their network behavior, enhancing the immunity to network rumors. All of these are depending on the "network literacy" of college students [17]. In 1994, Mc Clure, an American scholar, first proposed the concept of "network literacy", which includes two aspects of knowledge and skills, namely, the correct judgment and application of network knowledge, effective use of network skills, and considered these two positive standards to evaluate people's network literacy. The research of network literacy education theory stems from the concern of media literacy education. It is generally believed that network literacy should include such aspects as network cognition, information judgment, behavior management, ethics and morality, and security precautions, etc. In the current context of China's risk society, awareness and morality need to be emphasized and valued in the connotation of network literacy based on local culture. Only with rational consciousness and moral sense, when facing a large number of network information will not be easily deceived by false information, and will not easily spread some information based on perceptual knowledge. People living in the new media era are easily controlled by the network if they lack network literacy. Only when people have a higher level of network literacy, can they actively control various informations in the network and make a comprehensive interpretation and correct choice of information. This choice is a kind of ability to control one's emotional behavior, rationally express one's emotions, and also the ability to control network information [18].

As an important subject of network literacy education, Colleges and universities divide the strategy of network literacy education into two levels. On the one hand, with the wide integration of media tools and mobile communication technology, young students in the digital environment get rid of the group life of the real society and enter the virtual network space, which needs to rethink the relationship between "network" and people. On the other hand, adolescents' network literacy tends to focus more on the user knowledge and application of the learning level, more importantly, to cultivate the moral level of the network and the use of the network related skills [19].

\subsection{Cultivating Students' Perception of Network' Instrumentality and Practicability}

In fact, network literacy is actually the quality development of people as the propagating subject using network media tools. As the objective existence, the "network" can be transformed according to the subjective consciousness in the process of the subject's practice. Therefore, the "network" here essentially contains network information with dual nature: network information as a tool or a practice. When network information is used as a practical tool, it reflects the cognition and use process of the subject. From this perspective, there is a hypothesis about how the subject understands and uses tools, which directly determines the connotation of "goal orientation" and "network morality". When network information exists as a practical object, "network" is a process that can be constantly transformed by people's subjective consciousness, which is more related to the index range of "network skills" and "knowledge structure". Dialectical materialism holds that productive force includes three elements: the laborer, labor tools and the objects of labor, and the whole production process cannot be analyzed separately. In the process of network practice, the subject also uses network tools to transform network objects. Obviously, the cognition of network as a tool is the premise and foundation of the network practice [20]. Hence, to cultivate young students' network literacy, we must first solve the problem of network cognition, which is also the premise of not being trapped by network information and Internet rumors.

\subsection{Training Students' Value Rationality and Critical Cognition in Network Information Screening}

The rapid development of mobile Internet has increasingly torn life into "fragmentation". The change from "reading" to "browsing" reflects the changes in their attention. In the process of cultivating young students' network literacy, we should pay attention to the training of network information attention. Information screening and analysis focuses on critical cognition, so that young students can identify the value of information from the vast network information. People are always connected with network in the Internet social environment, thus changing the way we know the world and understand the world. Obviously, the picture of the world we see through the web is only the image the web provides us. But how exactly does the real world exist? Is it the same as the media's information? Young students who are the main part of netizens are unknown. At present, the Internet has penetrated into the daily life of contemporary young students, and the changes they have learned about the external world are largely the information provided by the Internet. With the explosive influx of daily information, teenagers, as the majority of netizens, should identify the authenticity of network information and whether it meets the mainstream value standards. The Internet society is a pluralistic existence, and everyone can connect with the world. College students need to cultivate their ability to identify information. Among all kinds of information, we should be able to distinguish the authenticity, usefulness and usefulness of information and its legality. Only in this way can we turn ourselves into the main subject of the network, so that we can keep rational and objective in the network information and rumors without following blindly.

\subsection{Cultivating Students' Awareness of Interactivity and Public Opinion Guidance in Network Information Transmission}

The network is originally only a carrier of information transmission, when the information on the Internet needs the active contribution from the network subjects. Without the participation of the network subjects, everyone is observing the 
behavior of others, and then the network world will not develop rapidly. Participation is an important step for individuals to move towards the Internet world. In the process of network participation, network interaction is formed, thus forming a network society. How to participate and what is involved are important criteria to judge the subjects' network literacy of the main body, and the emotion, aesthetics and moral accomplishment will be formed. Participation must be the method to train young students' network literacy. However, in the face of Internet rumors, simple participation is not enough. Because participation cannot change the flow of spread, or form a positive interaction. In the process of Internet communication, everyone is a network subject, these "individualized" individuals due to individual skills, quality, resources and other factors, cannot identify the authenticity of network information properly and often follow blindly[21]. Each subject can continue to spread information under the influence of others. In the flat network world, the ability of information exchange fission to drive public opinion is stronger in the network society. In this special information and network communication pattern, besides being cautious and not blindly following the trend, countercurrent challenge and refutation is also valuable, which will do well for the healthy development of the network environment. Pale negation is difficult to reverse the spread of rumors, and the reasonable interpretation is the key to guide information against rumors, and also the key of guiding irrational network information to disappear. Therefore, an important aspect of cultivating young students' network literacy is to understand the characteristics of information dissemination and interaction. In order to better reduce the spread of Internet rumors, the network environment needs the active participation of the network subjects and the positive communication.

\section{Conclusion}

According to the influences of Internet rumors on young students, this paper presents the education strategy of network literacy from educator's point of view, helping college students realize the instrumental characters of the network, keep the rational judgments for the values of network information, improve the discriminative ability about Internet rumors, and resist Internet rumors with themselves. Although it is still in the exploratory stage for universities to carry out network literacy education, the educators in universities have recognized that the network literacy is a necessary quality in the era of big data, which plays an important role in the developments of students. It is fundamental for the college students to possess good network literacies, realizing the network and using the network in a correct manner, which makes them meet the requirements of social developments and self-developments.

\section{Acknowledgements}

This work was supported by the Key Project of Ideological and Political Education of Jiangsu University (No. JDXGSA201605), the Special Foundation of College Counselors Work Research Association of Jiangsu Province
(No. 16FYHYB007), and the Foundation of University Philosophy and Social Sciences Research Project of Jiangsu Province (No. 2017SJBFDY158).

\section{References}

[1] Ai Mingjiang. Analysis on China's public security governance under the new situation: Cased by the rumor spread in the Internet [J]. Journal of Fujian Administration Institute, 2012, 531(2): 496-501.

[2] Li Xiaohong, Zhao Yange. Discussion on the Internet rumor administration in the view of the ethics [J]. Journal of Nanchang Normal University, 2015, 36(2): 9-13.

[3] Teng G P, Jin S H, Ying-Hua M A, et al. The Influence of New Media on University Freshmen's School Adaption and Education Countermeasures[J]. Journal of Northeastern University, 2015.

[4] Liu L. Study on the Negative Effects and Countermeasures to Deal with the Internet Rumors on University Campus[J]. Journal of Hubei Correspondence University, 2018.

[5] Jiang S. The Formation, Transmission of Internet Rumors and Guidance Mechanism of the Public Opinion[J]. Chongqing Social Sciences, 2012.

[6] Wang Z, Chen Y, Law S O, et al. The rule of law concept and the setting of principles in the governance of internet rumors $[\mathrm{J}]$. Journal of Liaoning Normal University, 2017.

[7] Chen H Y, Bai L. Research on the Ethicsanomie of Online Public Opinion in China[J]. Journal of Tianjin Sino-German University of Applied Sciences, 2017.

[8] Wang Q, Department M. Current Situation and Countermeasures of Treating Internet Rumors[J]. Journal of Fujian Administration Institute, 2016.

[9] Cao C. Network Literacy Education of College Students in the Context of Mobile Internet[J]. Guide of Science \& Education, 2017.

[10] Allport G W, Postman L. An analysis of rumor[J]. Public Opinion Quarterly, 1946, 10(4): 501-517.

[11] Kapferer J N. Rumeurs: le plus vieux média du monde[M]. Editions du seuil, 1987.

[12] Shibutani T, Improvised News: A Sociological Study of Rumor, Indianapolis, IN: Bobbs-Merrill, 1966.

[13] Bordia Prashant, Difonzo Nicholas. Problem solving in social Interactions on the Internet: Rumor as social cognition [J]. Social Psychology Quarterly, 2004, 67(1): 33-49.

[14] Bai Shuliang. Study on causes and countermeasures of Internet rumor [J]. Press Circles, 2010, 04: 82-83.

[15] AGNIESZKACZAPLICKA, Hołyst J A. MODELING OF INTERNET INFLUENCE ON GROUP EMOTION[J]. International Journal of Modern Physics C, 2012, 23(03):95-403.

[16] Chen Xi, Xiong Xi, Zhang Minghong, and Li Wei. Public authority control strategy for opinion evolution in social networks [J]. Chaos: An Interdisciplinary Journal of Nonlinear Science, 2016, 26(8): 083105. 
[17] McClure Charles R.. Network literacy: A role for libraries? [J]. Information Technology \& Libraries, 1994, 13(2): 115-125.

[18] Huang Yan. Method innovation of ideological and political education of college students [J]. Journal of Sichuan University of Science \& Engineering (Social Sciences Edition), 2015, 30(1): $34-46$

[19] Livingstone S. Internet literacy: young people's negotiation of new online opportunities[J]. Journal of Consumer Psychology, 2008, 8(1):91-111.
[20] Johnson G M. Functional Internet Literacy: Required Cognitive Skills with Implications for Instruction.[J]. E-Learning, 2007, 4(4):433-441.

[21] Lizhi M A, Marxism S O. Realistic Dilemma and Path Selection of Public Opinion Guidance When Emergency Events Happened in China[J]. Journal of North University of China, 2017. 